\title{
$80 \mathrm{MeV}$ carbon ion irradiation effects on advanced $200 \mathrm{GHz}$ silicon-germanium heterojunction bipolar transitors
}

\section{N.H. Vinayakprasanna ${ }^{1}$, K.C. Praveen ${ }^{1}$, N. Pushpa ${ }^{2}$, Ambuj Tripathi ${ }^{3}$, John D Cressler ${ }^{4}$, A.P. Gnana Prakash ${ }^{1^{*}}$}

${ }^{1}$ Department of Studies in Physics, University of Mysore, Manasagangotri, Mysore-570006, India

${ }^{2}$ Department of PG Studies in Physics, JSS College, Ooty Road, Mysore-570025, India

${ }^{3}$ Inter University Accelerator Centre (IUAC), New Delhi 110 067, India

${ }^{4}$ School of Electrical and Computer Engineering, Georgia Institute of Technology, Atlanta-30303, USA

*Corresponding author. Tel: (+91) 9590583920; E-mail: gnanaprakash@physics.uni-mysore.ac.in

Received: 24 August 2014, Revised: 08 November 2014 and Accepted: 15 November 2014

\section{ABSTRACT}

The total dose effects of $80 \mathrm{MeV}$ carbon ions and ${ }^{60} \mathrm{Co}$ gamma radiation in the dose range from $1 \mathrm{Mrad}$ to $100 \mathrm{Mrad}$ on advanced $200 \mathrm{GHz}$ Silicon-Germanium heterojunction bipolar transistors (SiGe HBTs) are investigated. The stopping and range of ions in matter (SRIM) simulation study was conducted to understand the energy loss of $80 \mathrm{MeV}$ carbon ions in SiGe HBT structure. Pre- and post-radiation DC figure of merits such as Gummel characteristics, excess base current, ideality factor, DC current gain, damage constant, neutral base recombination, avalanche multiplication of carriers and output characteristics were used to quantify the radiation tolerance of the devices. The excess base current, current gain and damage constant for $80 \mathrm{MeV}$ carbon irradiated SiGe HBTs show more degradation when compared to ${ }^{60} \mathrm{Co}$ gamma irradiation. The ideality factor for 80 $\mathrm{MeV}$ carbon ions irradiated SiGe HBTs is also more when compared to ${ }^{60} \mathrm{Co}$ gamma irradiated SiGe HBTs. The SiGe HBTs shows minimal degradation in current gain at collector current levels $(\sim 1 \mathrm{~mA})$ where the circuits are biased even after 100 Mrad of total dose. Therefore SiGe HBTs are became the reliable candidate for deep space exploration programs and high energy physics experiments (HEP) like large hadron colliders (LHCs). Copyright @ 2015 VBRI press.

Keywords: SiGe HBT; SRIM; ideality factor; ${ }^{60} \mathrm{Co}$ gamma radiation.
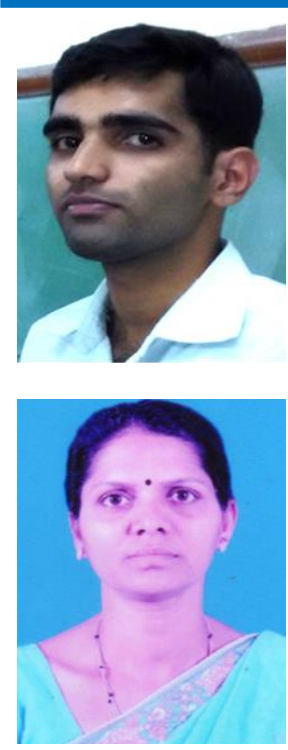

N.H. Vinayakaprasanna is a Junior Research Fellow (JRF) at Department of Physics, University of Mysore, Mysore, India. He did M Sc in Physics from University of Mysore and currently he is pursuing $\mathrm{Ph} \mathrm{D}$ in Physics at University of Mysore, Mysore, India. His main research interests include fabrication of semiconductor devices and studies on the effects of high energy swift heavy ion irradiation on silicon-germanium heterojunction bipolar transistors (SiGe HBTs).

N. Pushpa is an Assistant Professor at Department of PG Studies in Physics, JSS College, Ooty Road, Mysore, India. She completed M Sc in Nuclear Physics from Bangalore University, India and $\mathrm{Ph} \mathrm{D}$ from University of Mysore, India. She worked as Junior Research Fellow (JRF) and Senior Research Fellow (SRF) in DAE-BRNS Research Project at University of Mysore, India. She has more than 7 years of research/teaching experience and published more than 20 research articles in reputed journals. Her main research interests are radiation effects on different semiconductor devices like $\mathrm{Si}$ BJTs, SiGe HBTs and N-channel MOSFETs.

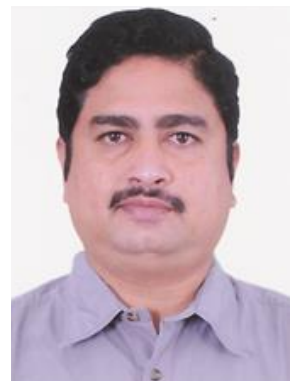

A.P. Gnana Prakash is an Associate Professor at Department of Physics, University of Mysore, Mysore, India. He completed M Sc and M Phil in Solid State Physics from Gulbarga University, India and $\mathrm{Ph}$ D from Mangalore University, India. He worked as a Post Doctoral Fellow at Department of Physics, National Dong Hwa University, Taiwan and School of Electrical and Computer Engineering, Georgia Institute of Technology, USA. He has more than 13 years of research/teaching experience and published more than 70 research articles in reputed journals. His main research interests are radiation effects on semiconductor devices and circuits. 


\section{Introduction}

The SiGe HBTs are emerging as leading contender among Si-BiCMOS technology and have attracted lots of attention for extreme environment applications such as military, space exploration programs and high energy physics experiments. These devices also exhibit excellent cryogenic performance, radiation tolerance without any radiation hardening and microwave power performance [1]. The SiGe HBT technology offers significant advantages over III-V technology in terms of integration levels for compact systems. In addition to this, SiGe HBT technology is totaldose radiation tolerant as fabricated, without any additional process modifications or layout changes. The reliability of $\mathrm{SiGe}$ HBTs in extreme environments is particularly important issue for high energy physics experiments, aerospace, military and space applications. Therefore, it is useful to investigate the total dose effects of heavy ions on semiconductor devices like SiGe HBTs in order to examine the reliability of SiGe HBTs in high dose radiation environments in shorter time interval. The accepted best practice is to use the conventional radiations such as gamma to examine the radiation tolerance of different semiconductor devices like metal oxide semiconductor (MOS) devices and transistors [2-5]. Therefore it is essential to compare ion irradiation results with ${ }^{60} \mathrm{Co}$ gamma irradiated results. Earlier studies have shown that the irradiation time taken to reach a particular total dose with gamma is higher when compared to ions [6]. Previously we have studied oxygen, fluorine and lithium ion irradiation effects on silicon NPN transistors and Nchannel MOSFETs $[\mathbf{7}, \mathbf{8}]$. The results show that, the degradation is almost similar for different high energy ions and ${ }^{60} \mathrm{Co}$ gamma radiation for NPN transistor but degradation is slightly more for ${ }^{60} \mathrm{Co}$ gamma irradiated Nchannel MOSFET when compared to different ions. The advantage of using high energy ion facility like Pelletron accelerator is, the irradiation time taken to reach a particular total dose is very less compared to gamma and other radiation facilities. Even though swift heavy ions (SHI) are able to induce modifications like vacancies, divacancies, point defects along with the ionization damage [9], the literature on the high energy ion irradiation effects on different electrical characteristics of SiGe HBTs is not available. Therefore in present investigation, we are studied the total dose effect of $80 \mathrm{MeV}$ carbon ion irradiation on I$\mathrm{V}$ characteristics of advanced $200 \mathrm{GHz}$ SiGe HBTs. This paper comprehensively discusses the advantages of SHI radiation hardness testing of SiGe HBTs over ${ }^{60} \mathrm{Co}$ gamma in the total dose ranging from 1 Mrad to $100 \mathrm{Mrad}$. In addition, the present work assesses the potential use of $\mathrm{SiGe} \mathrm{HBTs}$ in front-end electronics for emerging high energy physics experiments, including for possible use in the upgradation of the silicon strip detector and liquid argon calorimeter of the ATLAS detector as part of the LHC, CERN, Geneva, Switzerland [10, 11].

\section{Experimental}

\section{Materials}

The third generation $200 \mathrm{GHz}$ (8HP) SiGe HBTs designed and fabricated by IBM Microelectronics, USA are used in the present study. The SiGe HBT were selected by dicing a $200 \mathrm{~mm} \mathrm{SiGe}$ wafer and chips were wire bonded in a 28 pin dual in line package (DIP). The SiGe HBTs with an emitter area $\left(\mathrm{A}_{\mathrm{E}}\right)$ of $0.12 \times 2.0 \mu \mathrm{m}^{2}, 0.12 \times 4.0 \mu \mathrm{m}^{2}$ and $0.12 \times 8.0 \mu \mathrm{m}^{2}$ were chosen for $80 \mathrm{MeV}$ carbon and ${ }^{60} \mathrm{Co}$ gamma irradiation studies. The SiGe HBTs were exposed to 80 $\mathrm{MeV}$ carbon ions in 15 UD $16 \mathrm{MV}$ Pelletron Accelerator at Inter University Accelerator Centre (IUAC), New Delhi, India. The packages with SiGe HBTs were also exposed to ${ }^{60} \mathrm{Co}$ gamma radiation in Gamma Chamber-1200 (Model:GC-1200) manufactured by BRIT Mumbai at IUAC, New Delhi. The I-V characteristics of the pre- and post-irradiated devices were performed using computer interfaced Keithley 2636A dual source meter. The schematic cross section of SiGe HBT is shown in figure 1 and it does not show multiple levels of metallization layer above the SiGe HBT.

\section{Methods}

The $200 \mathrm{GHz}$ (8HP) SiGe HBTs consists Ge in base layer helps to speed up the mobility of electrons across the device. The boron dose in the as-grown $\mathrm{SiGe}$ base layer is $5 \times 10^{13} \mathrm{~cm}^{-2}$ [6]. The typical cut off frequency $\left(\mathrm{f}_{\mathrm{T}}\right)$ and maximum oscillation frequency $\left(\mathrm{f}_{\max }\right)$ are about $200 \mathrm{GHz}$ and $280 \mathrm{GHz}$ (at $300 \mathrm{~K}$ ) respectively and they exhibit 1.7 $\mathrm{BV}_{\mathrm{CEO}}$ and $0.12 \mu \mathrm{m} \mathrm{L}_{\text {eff. }}$ The SiGe HBTs were exposed to $80 \mathrm{MeV}$ carbon ions and ${ }^{60} \mathrm{Co}$ gamma radiation separately. All the terminals of transistors were grounded during the irradiation. The irradiation was performed in a room temperature $(300 \mathrm{~K})$ with fluence from $3.61 \times 10^{10}$ to $3.61 \times 10^{12}$ ions $/ \mathrm{cm}^{2}$ and the total equivalent dose ranges from $1 \mathrm{Mrad}$ to $100 \mathrm{Mrad}$. The devices were characterized at room temperature before and after irradiation. The important parameters such as the forward-mode and inverse-mode Gummel characteristics, excess base current $\left(\Delta \mathrm{I}_{\mathrm{B}}\right)$, normalized base current $\left(\mathrm{I}_{\mathrm{Bpost}} / \mathrm{I}_{\mathrm{Bpre}}\right)$, ideality factor $(\mathrm{n})$, DC current gain $\left(\mathrm{h}_{\mathrm{FE}}\right)$, neutral base recombination (NBR), avalanche multiplication (M-1) and the output characteristics $\left(\mathrm{I}_{\mathrm{C}}-\mathrm{V}_{\mathrm{CE}}\right)$ were measured. The results of SiGe HBTs with an emitter area $0.12 \times 2.0 \mu \mathrm{m}^{2}$ were presented in this paper and the devices with other geometries showed similar behaviour. The carbon ion irradiation results were compared with ${ }^{60} \mathrm{Co}$ gamma irradiation results with the same dose ranges.

\section{Results and discussion}

In order to understand the observed modification in the 80 $\mathrm{MeV}$ carbon ion irradiated SiGe HBTs, it is important to analyse the effect of irradiation on the device structure and the role of associated energy loss mechanisms. It is well known that when heavy ions impinge on a solid, they interact with the host nuclei and electrons via coulomb forces. These interactions lead to ionization or breaking bonds and displacement damage. If incident particle energy is sufficiently large, recoil atoms acquire energies in excess of the threshold energy for displacement damage. If incident particle energy is not sufficient to create displacement damage, the ion energy may be converted in to thermal energy or ions may possibly trapped at the defects [12]. 
In case of transistors, the high energy ion induced defects increases the generation-recombination (G/R) current in addition to defects leads to the degradation of minority carrier lifetime and in turn degrades the current gain of the transistors [13]. The schematic cross section of SiGe HBT is shown in Fig. 1-3 shows the 3-dimensional pictorial representation of $80 \mathrm{MeV}$ carbon ion induced displacement damage and ionization in SiGe HBTs respectively. When heavy ion enters in to a solid, it loses its energy via linear energy transfer (LET) and non-ionizing energy loss (NIEL).

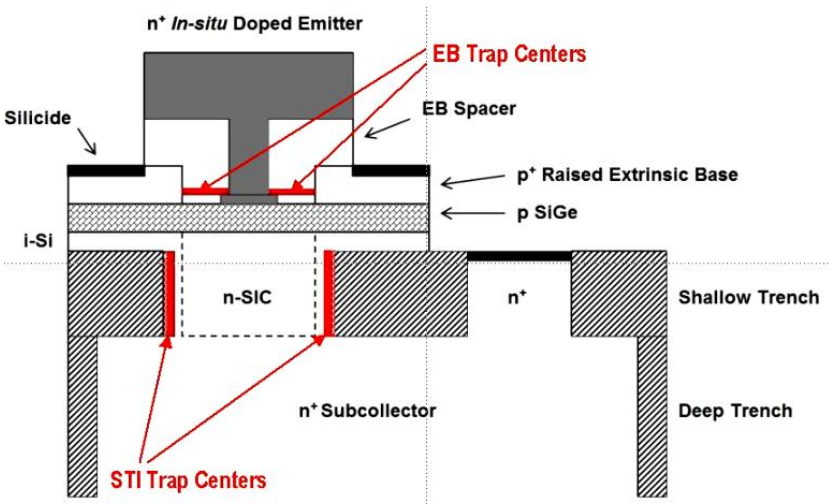

Fig. 1. The schematic device cross-section of $200 \mathrm{GHz}$ SiGe HBT.

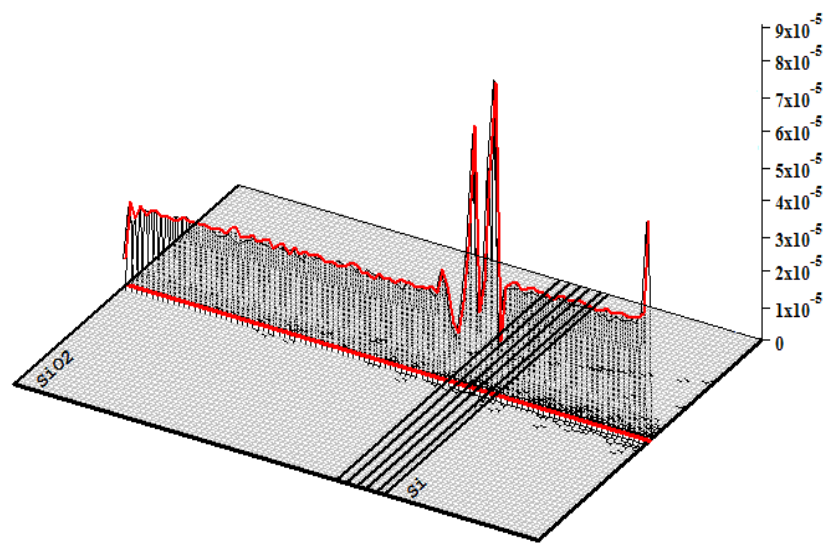

Fig. 2. SRIM simulations showing displacements (displacement/Å-ion) damage in $80 \mathrm{MeV}$ carbon ion irradiated SiGe HBT.

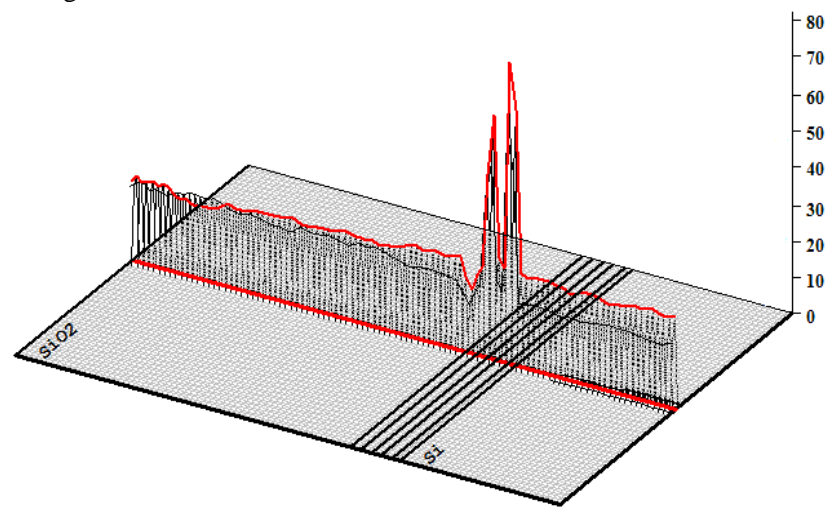

Fig. 3. SRIM simulations showing ionization (eV/Å-ion) in $80 \mathrm{MeV}$ carbon ion irradiated SiGe HBT.

The energy loss in different layers of SiGe HBT was calculated using SRIM-2011 [14]. From the SRIM simulation data it is revealed that each ion can creates around 30 vacancies before it stops deep inside the silicon substrate. Fig. 4 shows the variation of electronic energy loss and displacement energy loss in different layers of the SiGe HBT versus depth.

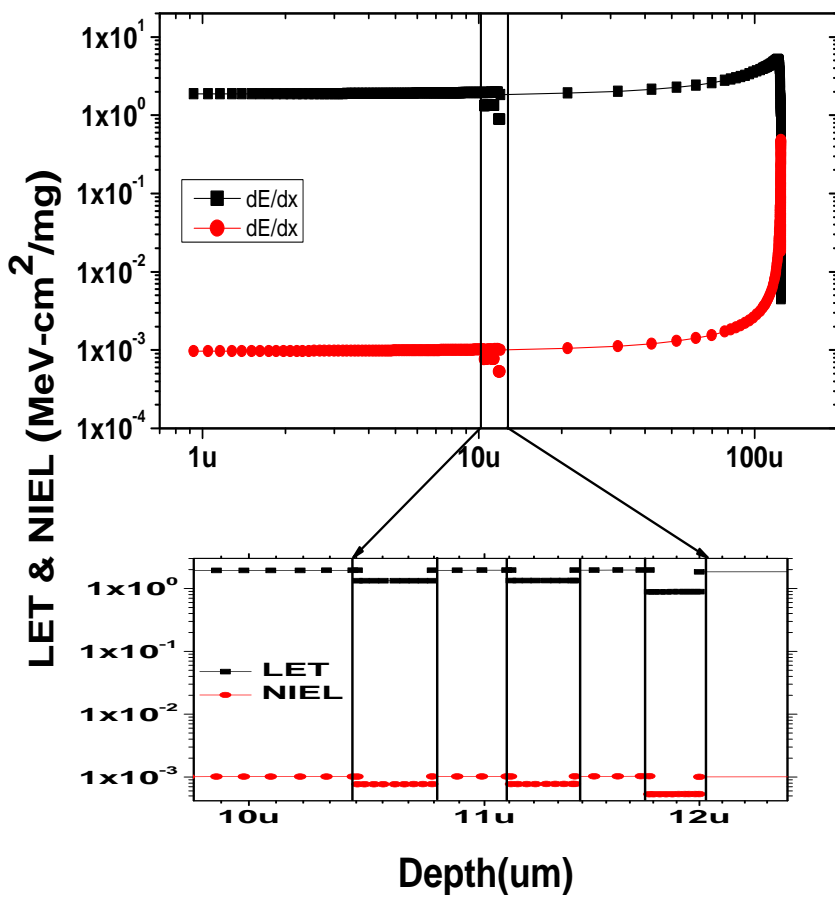

Fig. 4. Variation of energy loss of $80 \mathrm{MeV}$ carbon ion versus depth of SiGe HBT.

The conversion of ion fluence to equivalent cumulative total dose for heavy ions is given by the formula:

$$
\text { Dose }(\mathrm{rad})=1.6 \times 10^{-8} \times \mathrm{S} \times \Phi
$$

where, $\mathrm{S}$ is the sum of ionizing energy loss (LET) and displacement energy loss (NIEL) in $\mathrm{MeV}-\mathrm{cm}^{2} / \mathrm{mg}$, $\Phi$ is the fluence of carbon ion in ions $/ \mathrm{cm}^{-2}$ and $1.6 \times 10^{-8}$ is the conversion factor.

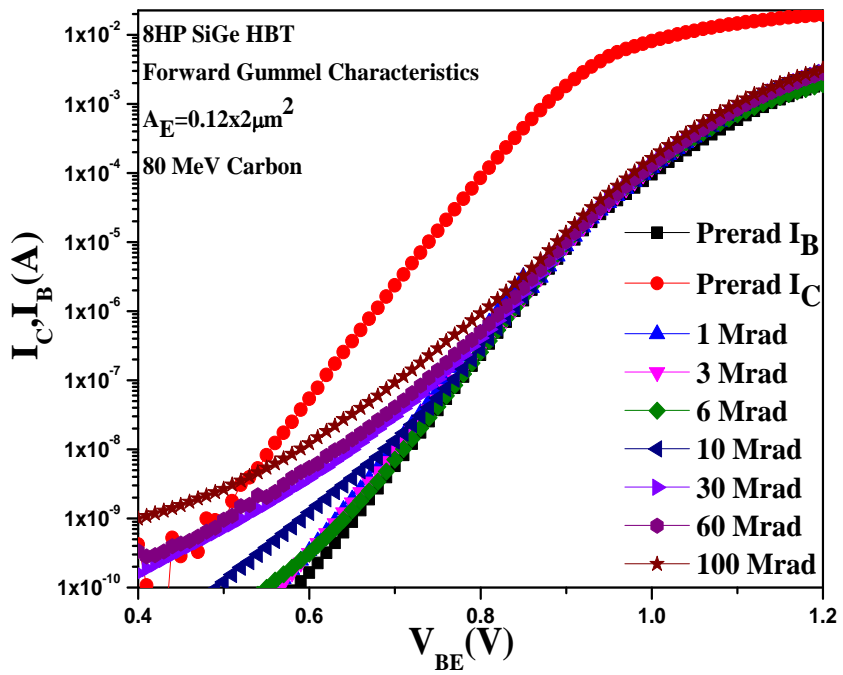

Fig. 5. Forward mode Gummel Characteristics of $80 \mathrm{MeV}$ Carbon ion irradiated SiGe HBT. 
The forward and inverse mode Gummel characteristics of $80 \mathrm{MeV}$ carbon ion irradiated SiGe HBTs are shown in Fig. 5 and Fig. 6 respectively. It can be clearly seen that, the base current $\left(\mathrm{I}_{\mathrm{B}}\right)$ increases with increase in ion dose at lower $\mathrm{V}_{\mathrm{BE}}$.

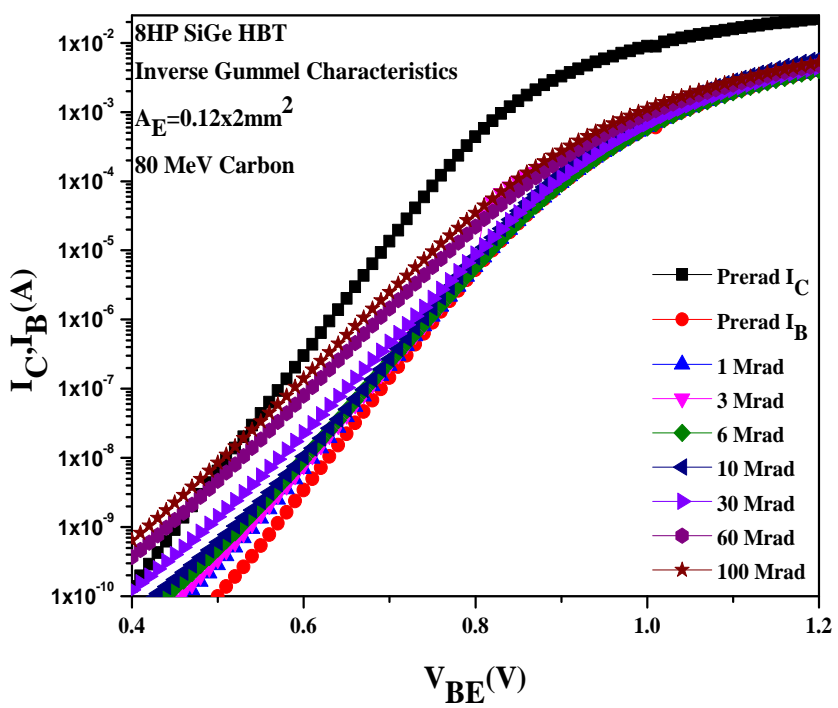

Fig. 6. Inverse mode Gummel Characteristics of $80 \mathrm{MeV}$ carbon ion irradiated SiGe HBT.

This classical signature of radiation induced damage in SiGe HBT is a result of radiation induced G/R trapped charges physically located near territory of the emitter-base (EB) spacer oxide (forward mode) and shallow trench isolation (STI) (inverse mode) oxide interface [15]. There is no variation in collector current $\left(\mathrm{I}_{\mathrm{C}}\right)$ with the increase in carbon dose, because the flow of electron through the base is not affected by the recombination in the depletion region. Therefore we have shown only pre- irradiation $\mathrm{I}_{\mathrm{C}}$ in Gummel plots.

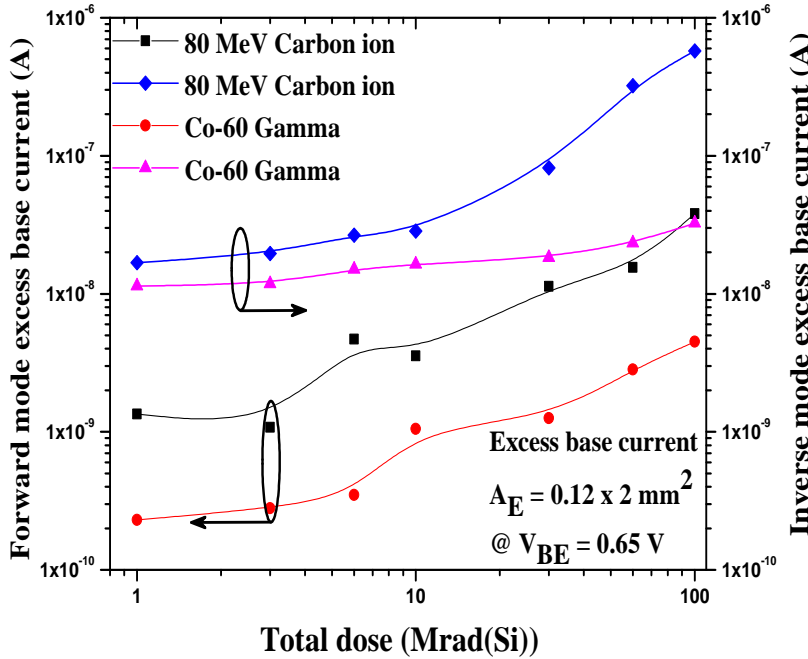

Fig. 7. The variation in forward mode and inverse mode excess base current at $\mathrm{V}_{\mathrm{BE}}=0.65 \mathrm{~V}$

Fig. 7 shows the forward mode and inverse mode excess base current $\left(\Delta \mathrm{I}_{\mathrm{B}}=\mathrm{I}_{\mathrm{Bpost}}-\mathrm{I}_{\mathrm{Bpre}}\right)$ for $80 \mathrm{MeV}$ carbon ion and ${ }^{60} \mathrm{Co}$ gamma irradiated SiGe HBTs. The increase in inverse mode $\Delta \mathrm{I}_{\mathrm{B}}$ is more when compared to forward mode
$\Delta \mathrm{I}_{\mathrm{B}}$ because, more number of $\mathrm{G} / \mathrm{R}$ trapping centers are sensed in STI oxide than EB spacer oxide. This increase in forward mode and inverse mode $\Delta \mathrm{I}_{\mathrm{B}}$ is comparatively more for $80 \mathrm{MeV}$ carbon ions than ${ }^{60} \mathrm{Co}$ gamma radiation. It can be also seen that the increase in forward mode and inverse mode $\Delta \mathrm{I}_{\mathrm{B}}$ is an order of one magnitude more for carbon ion irradiated SiGe HBTs when compared to ${ }^{60} \mathrm{Co}$ gamma irradiated SiGe HBTs.

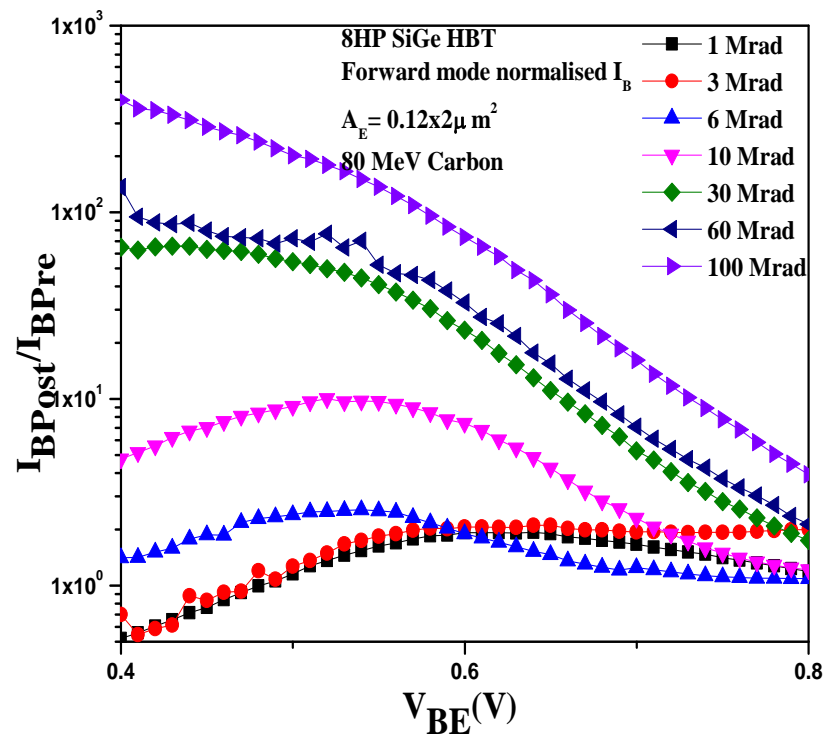

Fig. 8. Forward mode normalised base current of $80 \mathrm{MeV}$ Carbon ion irradiated SiGe HBT.

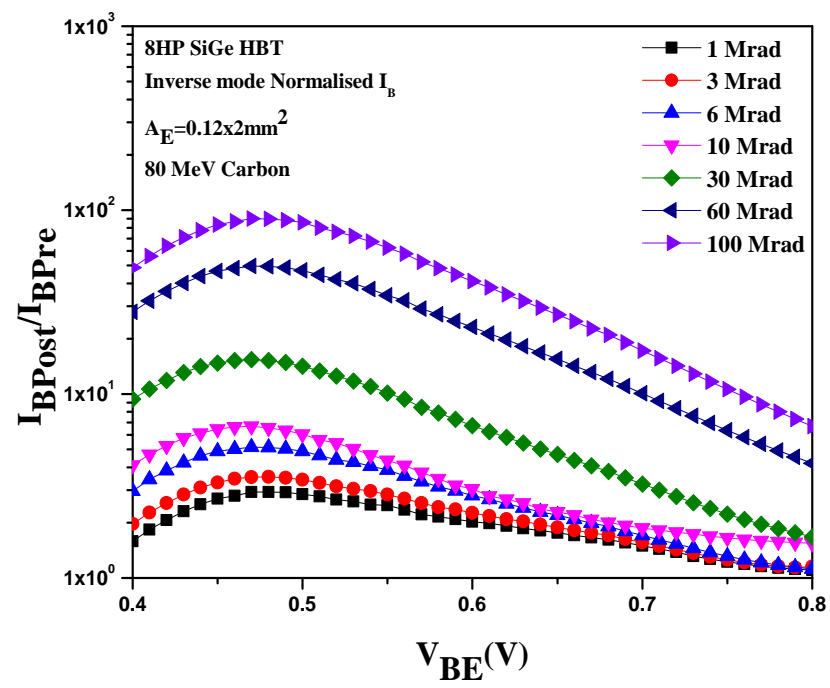

Fig. 9. Inverse mode normalised base current of $80 \mathrm{MeV}$ Carbon ion irradiated SiGe HBT.

Fig. 8 and Fig. 9 shows forward mode and inverse mode normalised base current for $80 \mathrm{MeV}$ carbon ion irradiated SiGe HBTs respectively. From the figure 8 it is clear that the $I_{B}$ is significantly increased at lower $V_{B E}$ with increasing carbon ion dose. The characteristic increase in low injection base current is caused by radiation induced $\mathrm{G} / \mathrm{R}$ trap centers in EB spacer oxide as explained above. Fig. 9 confirms that, after every subsequent cumulative dose the trapped charges built up in the STI oxide. The oxide trapped charges near the silicon/oxide interface increase the depletion region near the CB junction. Hence, 
the inverse mode $I_{B}$ increases with increasing charge builtup near the STI oxide. From the above plots (Fig. 8 and 9), one can say that, carbon ions can create more damage in STI oxide when compared to EB spacer oxide.

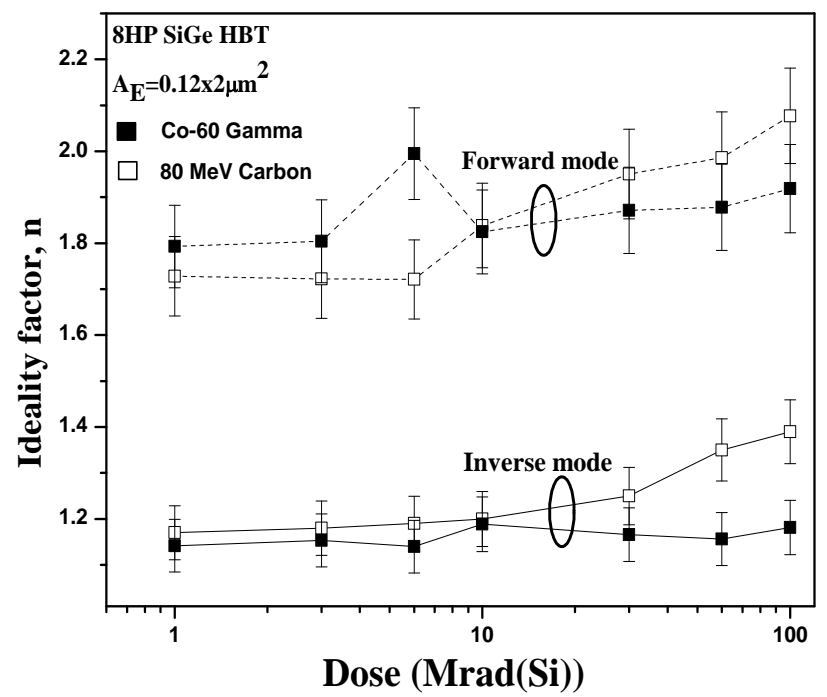

Fig. 10. The ideality factor versus total dose.

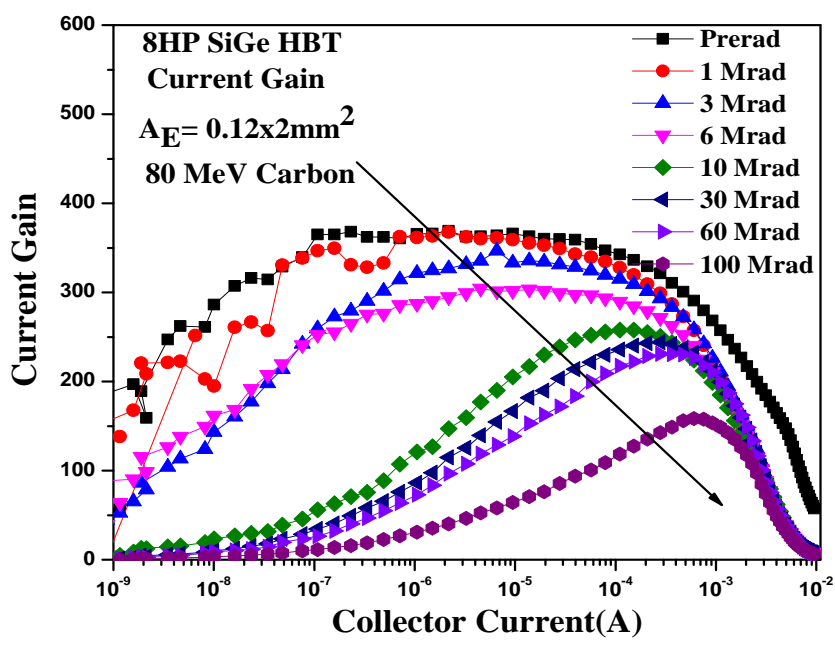

Fig. 11. The variation in current gain after $80 \mathrm{MeV}$ carbon ion irradiation.

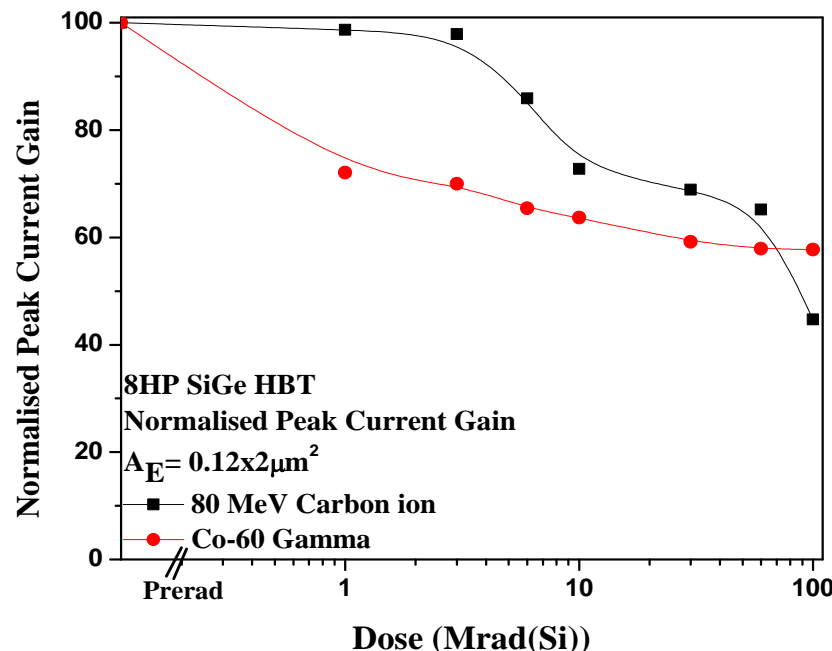

Fig. 12. Normalised peak current gain versus total dose for $80 \mathrm{MeV}$ carbon ion irradiated SiGe HBT.
The forward and inverse base current ideality factor ' $n$ ' was extracted at $\mathrm{V}_{\mathrm{BE}}=0.6 \mathrm{~V}$ as a function of radiation dose for $80 \mathrm{MeV}$ carbon and ${ }^{60} \mathrm{Co}$ gamma irradiation. Generally ' $n$ ' have a value between 1 and 2 . If ' $n$ ' is close to 1 , the diffusion current dominates $I_{B}$. While ' $n$ ' is close to 2 then recombination current dominates $I_{B}[16]$. From the Fig. 10, it can be seen that ' $\mathrm{n}$ ' is increased slightly as a function of radiation dose. Forward mode ideality factor is found to be increased from 1.7 to 2.0 for $80 \mathrm{MeV}$ carbon ion irradiated $\mathrm{SiGe} \mathrm{HBT}$, whereas for ${ }^{60} \mathrm{Co}$ gamma irradiation ' $\mathrm{n}$ ' increased from 1.8 to 1.9 . In the case inverse mode, ' $n$ ' for $80 \mathrm{MeV}$ carbon ion irradiation increased from 1.1 to 1.4 and for ${ }^{60} \mathrm{Co}$ gamma irradiation ' $\mathrm{n}$ ' increased from 1.14 to 1.18. The increase in ' $n$ ' is due to the space charge region recombination centers around the periphery of the EB depletion region.

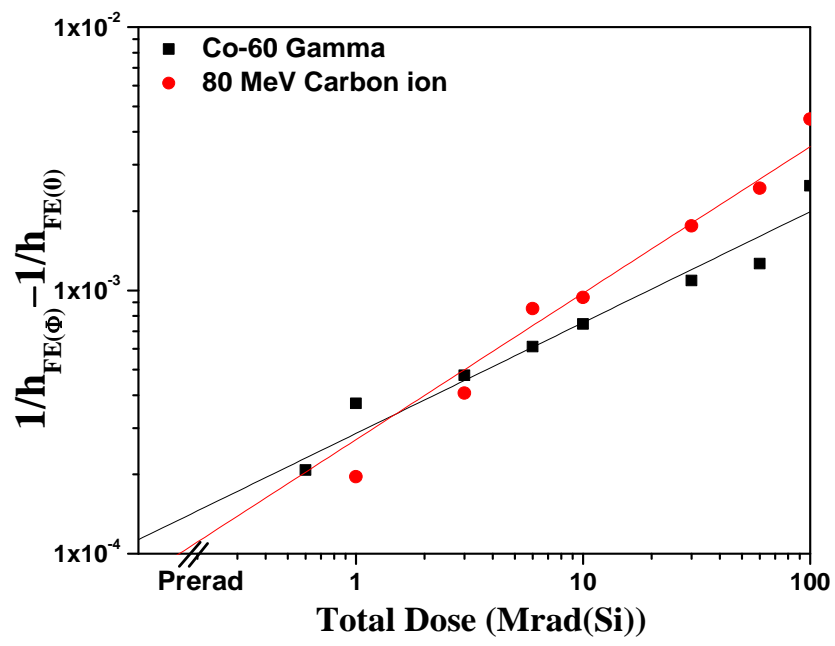

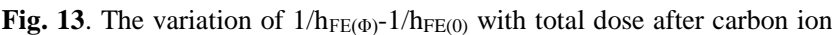
and ${ }^{60} \mathrm{Co}$ gamma irradiation.

The Fig. 11 shows the degradation in current gain for different doses and it can be seen that, the current gain $\left(\mathrm{h}_{\mathrm{FE}}\right)$ decreases with increase in dose. As carbon dose increases the peak current gain shifts towards higher $\mathrm{I}_{\mathrm{C}}$ or higher $\mathrm{V}_{\mathrm{BE}}$. The current gain curves for different carbon doses tend to merge as $\mathrm{I}_{\mathrm{C}}$ increases and it indicates that, the gain degradation is small at higher base currents and quasi neutral base region recombination is not significantly affected by carbon ion irradiation [17]. Fig. 12 shows the comparison of normalised peak current gain versus total dose for $80 \mathrm{MeV}$ carbon ion and ${ }^{60} \mathrm{Co}$ gamma irradiated SiGe HBTs. As radiation doses increases, the peak current gain decreases because of the non ideal $\mathrm{I}_{\mathrm{B}}$ increases with increase in radiation dose. After $100 \mathrm{Mrad}$ of total dose, the peak current gain is found to be decreased by $55 \%$ for 80 $\mathrm{MeV}$ carbon ion irradiated SiGe HBTs and $42 \%$ for gamma irradiated SiGe HBTs. The SiGe HBTs shows minimal degradation in current gain at collector current levels $(\sim 1$ $\mathrm{mA}$ ) where the circuits are biased even after $100 \mathrm{Mrad}$ of total dose.

Fig. 13 shows the variation of $1 / \mathrm{h}_{\mathrm{FE}(\Phi)}-1 / \mathrm{h}_{\mathrm{FE}(0)}$ with total dose for $80 \mathrm{MeV}$ carbon ion and ${ }^{60} \mathrm{Co}$ gamma radiation. The displacement damage constant can be obtained from Messenger-Spratt equation [18];

$$
1 / \mathrm{h}_{\mathrm{FE}(\Phi)}=1 / \mathrm{h}_{\mathrm{FE}(0)}+\mathrm{K} \Phi
$$


where $1 / \mathrm{h}_{\mathrm{FE}(0)}$ is the initial reciprocal gain (before irradiation), $\mathrm{K}$ is the composite displacement damage factor and $\Phi$ is the incident radiation dose. The damage constant was found to be $0.5563 \pm 0.03 \mathrm{Mrad}^{-1}$ for $80 \mathrm{MeV}$ carbon and $0.4061 \pm 0.03 \mathrm{Mrad}^{-1}$ for ${ }^{60} \mathrm{Co}$ gamma radiation. It can be seen that, the damage constant is more for $80 \mathrm{MeV}$ carbon ion irradiated SiGe HBTs when compared to ${ }^{60} \mathrm{Co}$ gamma irradiated SiGe HBTs.

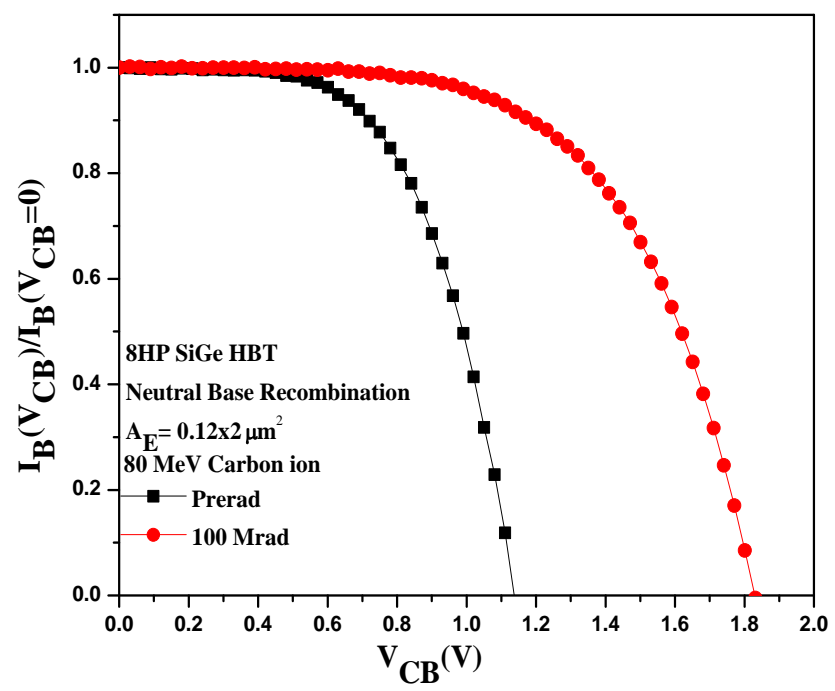

Fig. 14. Neutral base recombination for $80 \mathrm{MeV}$ carbon ion irradiated SiGe HBT.

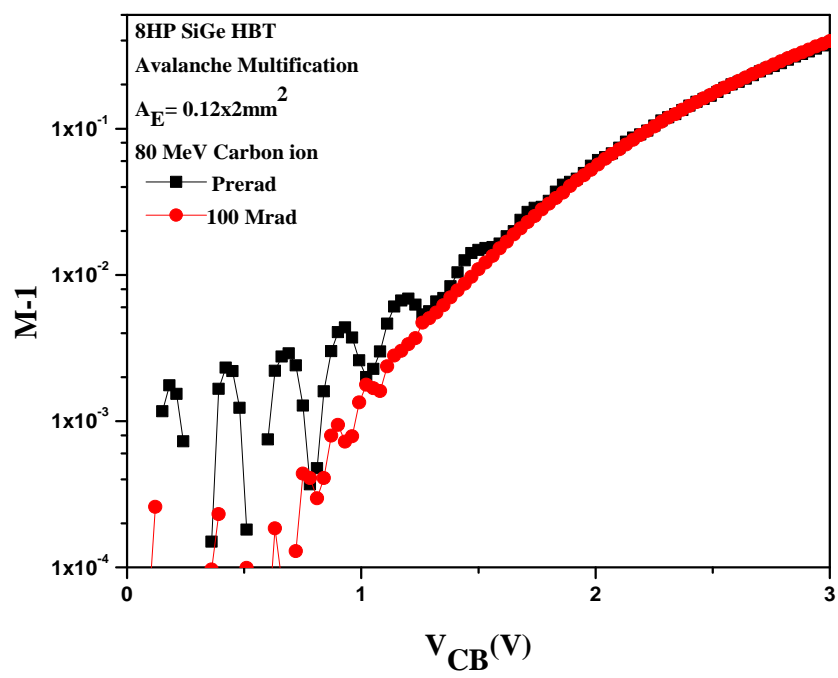

Fig. 15. The avalanche multiplication of carriers for $80 \mathrm{MeV}$ carbon ion irradiated SiGe HBT.

Fig. 14 shows the neutral base recombination (NBR) results for $80 \mathrm{MeV}$ carbon ion irradiated SiGe HBT. The carbon ion induced trap states before and after irradiation in the base region can be accessed through the NBR studies. The base current increases with increase in the base recombination and in turn decreases the current gain [19]. From (Fig. 14) it is clear that the slope of NBR curve at lower $\mathrm{V}_{\mathrm{CB}}$ is same for pre-rad and $100 \mathrm{Mrad}$ curves. This indicates that, there is negligible amount of damage in the neutral base region even after 100 Mrad total dose. However the collector base voltage $\left(\mathrm{BV}_{\mathrm{CBO}}\right)$ increases with increase in radiation total dose. It can be seen that the breakdown voltage $\left(\mathrm{BV}_{\mathrm{CBO}}\right)$ is $1.16 \mathrm{~V}$ for unirradiated $\mathrm{SiGe}$
HBT and $1.83 \mathrm{~V}$ after $100 \mathrm{Mrad}$ of total dose. The radiation induced electric field in the $\mathrm{CB}$ junction negatively impacts the device performance after irradiation. We have also studied the effect of carbon ion irradiation on the avalanche multiplication (M-1) of carriers in the $\mathrm{CB}$ junction. Fig. 15 illustrates the measured multiplication factor i.e., the number of electron-hole pairs created in the $\mathrm{CB}$ space-charge region as a function of $\mathrm{V}_{\mathrm{CB}}$. The decrease in the M-1 is very small even after 100 Mrad of total dose, hence the electron/hole pairs created in the CB spacecharge region is unable to multiplicate the impact ionization with lattice atoms due to the formation of displacement damages by carbon ion irradiation [6].

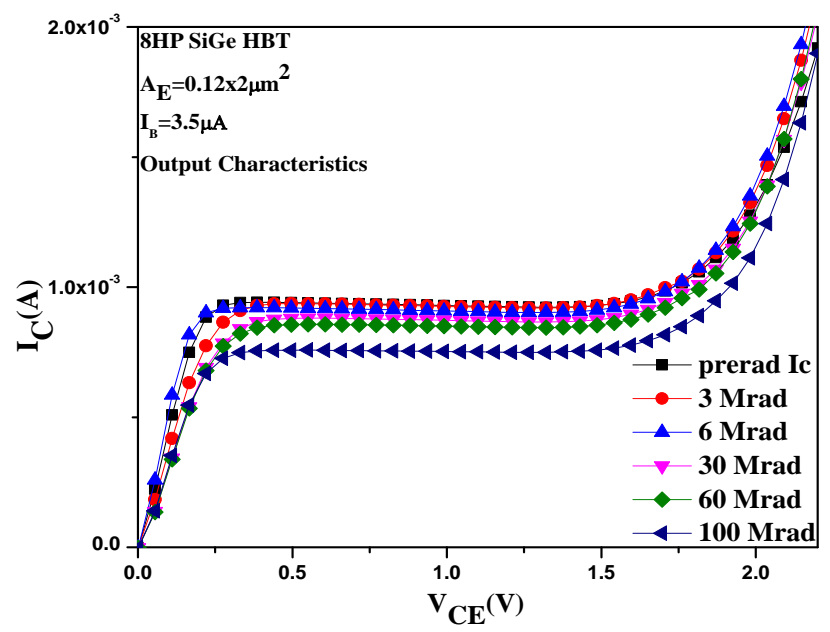

Fig. 16. Output Characteristics for $80 \mathrm{MeV}$ carbon ion irradiated $\mathrm{SiGe}$ HBT.

Fig. 16 shows the output characteristics of $80 \mathrm{MeV}$ carbon ion irradiated SiGe HBT at $\mathrm{I}_{\mathrm{B}}=2.25 \mu \mathrm{A}$ and it can be seen that the collector current $\left(\mathrm{I}_{\mathrm{C}}\right)$ decreases with increase in ion dose. The $\mathrm{I}_{\mathrm{C}}$ was about $0.96 \mathrm{~mA}$ before irradiation and after $100 \mathrm{Mrad}$ total dose of carbon ion, $\mathrm{I}_{\mathrm{C}}$ drops to $0.72 \mathrm{~mA}$. When high LET radiation enters to $\mathrm{SiGe}$ HBTs creates various types of point defects and their complexes in $\mathrm{CB}$ junction. The radiation induced defect formation in $\mathrm{SiGe} \mathrm{HBT}$ structure also responsible for degradation in $\mathrm{I}_{\mathrm{C}}[\mathbf{2 0}]$.

\section{Conclusion}

The total dose effects of $80 \mathrm{MeV}$ carbon ions and ${ }^{60} \mathrm{Co}$ gamma radiation on the $\mathrm{I}-\mathrm{V}$ characteristics of advanced 200 $\mathrm{GHz} \mathrm{SiGe}$ HBTs were studied systematically. The results of $80 \mathrm{MeV}$ carbon ion irradiated SiGe HBTs were compared with ${ }^{60} \mathrm{Co}$ gamma irradiation results in the total dose ranging from 1 Mrad to $100 \mathrm{Mrad}$. SRIM software is used to estimate the LET and NIEL of the carbon ion in different layers of SiGe HBTs. From the SRIM calculation it is clear that chosen carbon ion energy $(80 \mathrm{MeV})$ is sufficient to cross the metallization layers and active region of SiGe HBTs. The SRIM simulation results show that ionization is almost uniform in metallization layer and active region of the transistor. The base current of irradiated SiGe HBTs is found to be increase with increase in the total dose. The current gain of the irradiation $\mathrm{SiGe}$ HBTs were found to degrade significantly after irradiation. The damage constant is more for $80 \mathrm{MeV}$ carbon ion 
irradiated SiGe HBTs when compared to ${ }^{60} \mathrm{Co}$ gamma irradiated SiGe HBTs. The ideality factor increases with increase in radiation dose and it is close to a value 2 after $100 \mathrm{Mrad}$ total dose. The degradation in the electrical characteristics of SiGe HBTs is mainly due to the G/R trap centers created in the EB spacer oxide and displacement damage in the bulk of the transistor. The peak $\mathrm{h}_{\mathrm{FE}}$ of the SiGe HBTs irradiated with both radiations is well above 100. Therefore $h_{\mathrm{FE}}$ of irradiated SiGe HBTs is acceptable even after $100 \mathrm{Mrad}$ of radiation total dose. The inherent radiation tolerance of $200 \mathrm{GHz}$ SiGe HBTs makes them a leading candidate for designing integrated front-end circuits for readout ASICs for use in an upgraded LHC and for space exploration programs. The irradiation time taken for $80 \mathrm{MeV}$ carbon ion to reach $100 \mathrm{Mrad}$ of total dose is considerably less when compared to ${ }^{60} \mathrm{Co}$ gamma irradiation facilities. Therefore high energy ion irradiation facilities can be used for accelerated total dose studies.

\section{Acknowledgements}

The authors would like to thank Dr. D. Kanjilal, Dr. D. K. Avasthi, and Dr. K. Asokan, IUAC, New Delhi for providing the experimental facilities. This work is carried out under the research project sanction by Department of Science and Technology (DST), Government of India (Project No. SR/S2/CMP-0034/2012).

\section{Reference}

1. Cressler, J. D. Proceedings of the IEEE, 2005, 93, 1559. DOI: 10.1109/JPROC.2005.852225

2. Roldan, J.; Ansley, W. E.; Cressler, J.; Clark, S.; Nguyen Ngoc, D. IEEE Transactions on Nuclear Science, 1997, 44, 1965. DOI: $10.1109 / 23.658970$

3. Cressler, J.; Hamilton, M. C.; Mullinax, G. S.; Li, Y.; Niu, G.; Marshall, C. J.; Marshall, P. W.; Kim, H. S.; Palmer, M. J.; Joseph, A. J. IEEE Transactions on Nuclear Science, 2000, 47, 2515. DOI: $10.1109 / 23.903801$

4. Han, Bo; Huang Wang; Jianjun Gao, International Journal of Electronics, 2014, 101, 10.

DOI: $10.1080 / 00207217.2013 .769182$

5. Sun Yabin; Jun Fu; Jun Xu; Yudong Wang; Wei Zhou; Wei Zhang; Jie Cui; Gaoqing Li; Zhihong Liu, Physica B: Condensed Matter, 2014, 449,186 .

DOI: $10.1016 /$ j.physb.2014.05.033

6. Praveen, K. C.; Pushpa, N.; Cressler, J. D.; Gnana Prakash A. P. J. Nano- Electron. Phys, 2011, 3, 348.

7. Pushpa, N.; Gnana Prakash, A. P.; Praveen, K. C.; Cressler, J. D.; Revannasiddaiah, D. Radiation Effects \& Defects in Solids, 2009, $164,592$. DOI: $10.1080 / 10420150903173288$

8. Pushpa, N.; Praveen, K. C.; Gnana Prakash, A. P.; Prabhakara Rao, Y. P.; Ambuj Tripati,; Govindaraj,; G. Revannasiddaiah, D. Nuclear Instruments and Methods in Physics Research Section A: Accelerators, Spectrometers, Detectors and Associated Equipment, 2010, 613, 280. DOI: $10.1016 /$ j.nima.2009.12.015

9. Kumar, M. V.; Verma, S.; Shobha, V.; Jayashree, B.; Kanjilal, D.; Ramani, R.; Krishnaveni, S. Journal of Materials Science Research, 2014, 3, 24 .

DOI: $10.5539 / \mathrm{jmsr} . v 3 \mathrm{n} 3 \mathrm{p} 24$

10. Madhu, K. V.; Kulkarni, S. R.; Ravindra, M.; Damle, R. Nuclear Instruments and Methods in Physics Research Section B: Beam Interactions with Materials and Atoms, 2007, 254, 98.

DOI: $10.1016 /$ j.nimb.2006.10.063

11. Gnana Prakash, A. P.; Ke, S. C.; Siddappa, K. Nuclear Instruments and Methods in Physics Research Section B: Beam Interactions with Materials and Atoms, 2004, 215, 457.

DOI: $10.1016 /$ j.nimb.2003.09.015

12. Joshi, A. B.; Ramesh, K.; Rakesh Lal; Technical report no. $\mathrm{RAD} / \mathrm{TR} / 90 / 03$

13. Praveen, K. C.; Pushpa, N.; Prabakara Rao, Y.; Govindaraj, G.; Cressler, J. D.; Gnana Prakash, A. P. Solid-state electronics, 2010, 54,
1554.

DOI: $10.1016 /$ j.sse.2010.08.003

14. Ziegler, J. F.; Biersack, J. P.; Ziegler, M. D.; Nuclear Instruments and Methods in Physics Research Section B: Beam Interactions with Materials and Atoms, 2010, 268, 1818.

DOI: $10.1016 /$ j.nimb.2010.02.091

15. Sutton, A. K.; Haugerud, B. M.; Prakash, A. G.; Jun, B.; Cressler, J. D.; Marshall, C. J.; Marshall, P. W.; Ladbury, R.; Guarin, F.; Joseph, A. J. IEEE Transactions on Nuclear Science, 2005, 52, 2358.

DOI: $10.1109 /$ TNS.2005.860728

16. Sutton, A. K.; Prakash, A. G.; Jun, B.; Zhao, E.; Bellini, M.; Pellish, J.; Diestelhorst, R. M.; Carts, M. A.; Phan, A.; Ladbury, R. IEEE Transactions on Nuclear Science, 2006, 53, 3166. DOI: $10.1109 /$ TNS.2006.885382

17. Shatalov, A. Ph.D Thesis, 2000. URI: http://hdl.handle.net/1957/33262

18. Messenger G.; Spratt, J. Proceedings of the IRE, 1958, 46, 1038. DOI: $10.1109 /$ JRPROC.1958.286841

19. Praveen, K. C., Ph.D. Thesis, University of Mysore, 2013.

20. YaBin Sun; Jun Fu; Jun Xu; YuDong Wang; Wei Zhou; Wei Zhang; Jie Cui; Gao Qing Li; ZhiHong Liu, Nuclear Instruments and Methods in Physics Research Section B: Beam Interactions with Materials and Atoms, 2013, 312, 77. DOI: $\underline{10.1016 / \mathrm{j} . \mathrm{nimb} .2013 .07 .013}$ 